\title{
Systems Biology Approach for Identification of Essential Growth Factors in Retinal Regeneration
}

\section{Zahra-Soheila Soheili, PhD; Hamid Latifi-Navid, MS}

Department of Molecular Medicine, National Institute of Genetic Engineering and Biotechnology, Tehran, Iran

ORCID:

Zahra-Soheila Soheili: https://orcid.org/0000-0003-1292-465X

J Ophthalmic Vis Res 2021; 16 (1): 1-2

Tissue engineering may be considered as a potential treatment modality for various types of retinal diseases. Retinal regeneration depends on an optimal combination of scaffolds, cells, and growth factors. Growth factors play a fundamental role in a variety of cellular processes such as proliferation, migration, differentiation, and multicellular morphogenesis. ${ }^{[1]}$ Growth factors expedite tissue growth/regeneration by providing the right signals to the cells. ${ }^{[2]}$ Systems biologyrelated approaches help us understand the mechanisms underlying retinal tissue engineering and investigate the effect of growth factors through protein-protein interaction network analyses. Network centrality analysis using different criteria has the potential to reveal growth factors important for retinal regeneration.

In the current issue of Journal of Ophthalmic and Vision Research, Beheshtizadeh et al report an in-silico study which was aimed to determine the most important growth factors in retinal tissue engineering. ${ }^{[3]}$ Gene ontology (GO) and degree centrality analysis were used to identify the most effective proteins for retinal regeneration. Despite the remarkable results presented in the study, it should be stressed that the growth factors were determined only by degree centrality analysis. Numerous studies have established that low connectivity growth factors may also be considered critical in biological processes and for network integrity. ${ }^{[4,5]}$

There are several types of centrality which include degree, closeness, between-ness, centroid value, bridging, eccentricity, and eigenvector centrality. Degree centrality is used to evaluate the regulatory importance of immediate neighboring nodes. Nodes with high degree centrality interact with different proteins and therefore usually play a key regulatory role in the network. The short average distance of a distinct node to the entire network of proteins is represented by the closeness index. Proteins with high closeness index (compared to the network) impose a fundamental regulatory effect on other proteins and will be significantly affected by changes in the network. Between-ness index represents the number of times that a specific node (via the shortest path) is used to hold communicating proteins together. The coherence and functionality of the network are likely maintained by the betweenness centrality index. To determine the functional ability of a distinct node to orchestrate discrete clusters of proteins, centroid value is used in the network. Nodes with high centroid values coordinate the activity of other clusters to regulate a distinct cell function. Bridging centrality index is employed to distinguish nodes that link clusters or densely connected regions. Eccentricity index is used to distinguish nodes which are easily reachable by all other proteins. Therefore, a protein with high eccentricity index affects, or gets more easily affected by, other proteins. To determine nodes with a central super-regulatory role or those that serve as key targets of a regulatory pathway, the eigenvector centrality index is used. ${ }^{[6]}$

In summary, to comprehensively understand the importance of each node in any given network, different kinds of centrality analyses should be performed. Moreover, integration of centrality analyses results helps one correct selection of the most important nodes in the network. It is highly recommended to use web servers such as DAVID (Database for Annotation, Visualization, and Integrated Discovery; https://david.ncifcrf.gov/) or Enrichr (https://maayanlab.cloud/Enrichr/) which have been specifically developed for gene ontology (GO) and enrichment analyses. ${ }^{[7,8]}$ Moreover, there exists a need for developing a 
software which integrates servers that test for GO category enrichment via recruiting the output and provide the resources for summarizing and visualizing data.

\section{REFERENCES}

1. Ren X, Zhao M, Lash B, Martino MM, Julier Z. Growth factor engineering strategies for regenerative medicine applications. Front Bioeng Biotechnol 2019;7:469.

2. Vasita R, Katti DS. Growth factor-delivery systems for tissue engineering: a materials perspective. Expert Rev Med Devices 2006;3:29-47.

3. Beheshtizadeh N, Baradaran-Rafii A, Sistani MS, Azami M. An In-Silico Study on the Most Effective Growth Factors in Retinal Regeneration using Tissue Engineering Concepts. J Ophthalmic Vis Res 2021;16:56-67.

\section{Correspondence to:}

Zahra-Soheila Soheili, PhD. Department of Molecular Medicine, National Institute of Genetic Engineering and Biotechnology, Tehran, Iran. Email: zssoheili@gmail.com academic: soheili@nigeb.ac.ir

Received: 14-12-2020

Accepted: $23-12-2020$

\section{Access this article online}

Website: https://knepublishing.com/index.php/JOVR

DOI: 10.18502/jovr.v16i1.8242
4. Tew KL, Li XL, Tan SH. Functional centrality: detecting lethality of proteins in protein interaction networks. Genome Inform 2007;19:166-177.

5. Mahadevan R, Palsson BO. Properties of metabolic networks: structure versus function. Biophys $J$ 2005;88:L07-L09.

6. Jalili M, Salehzadeh-Yazdi A, Gupta S, Wolkenhauer O, Yaghmaie M, Resendis-Antonio $\mathrm{O}$, et al. Evolution of centrality measurements for the detection of essential proteins in biological networks. Front Physiol 2016;7:375.

7. Huang DW, Sherman BT, Tan Q, Collins JR, Alvord WG, Roayaei J, et al. The DAVID gene functional classification tool: a novel biological module-centric algorithm to functionally analyze large gene lists. Genome Biol 2007;8:R183.

8. Kuleshov MV, Jones MR, Rouillard AD, Fernandez NF, Duan Q, Wang Z, et al. Enrichr: a comprehensive gene set enrichment analysis web server 2016 update. Nucleic Acids Res 2016;44:W90-W97.

This is an open access journal, and articles are distributed under the terms of the Creative Commons Attribution-NonCommercial-ShareAlike 4.0 License, which allows others to remix, tweak, and build upon the work non-commercially, as long as appropriate credit is given and the new creations are licensed under the identical terms.

How to cite this article: Soheili Z-S, Latifi-Navid H. Systems Biology Approach for Identification of Essential Growth Factors in Retinal Regeneration. J Ophthalmic Vis Res 2021;16:1-2. 